\title{
Copaiba Oil and Its Constituent Copalic Acid as Chemotherapeutic Agents against Dermatophytes
}

\author{
Marcela T. Nakamura, ${ }^{a}$ Eliana H. Endo, ${ }^{b}$ João Paulo B. de Sousa, ${ }^{a}$ Daniel R. Callejon, ${ }^{a}$ \\ Tânia Ueda-Nakamura, ${ }^{b}$ Benedito P. Dias Filho, ${ }^{b}$ Osvaldo de Freitas, ${ }^{a}$ \\ Celso V. Nakamura ${ }^{b}$ and Norberto P. Lopes* ${ }^{* a}$
}

\author{
${ }^{a}$ Faculdade Ciências Farmacêuticas de Ribeirão Preto, Universidade de São Paulo (USP), \\ Av. Do Café s/n, 14040-903 Ribeirão Preto-SP, Brazil \\ ${ }^{b}$ Departamento de Ciências Básicas da Saúde, Laboratório de Inovação Tecnológica no \\ Desenvolvimento de Fármacos e Cosméticos, Universidade Estadual de Maringá, \\ Av. Colombo 5790, 87020-900 Maringá-PR, Brazil
}

\begin{abstract}
Copaiba oil, an oleoresin extracted from Copaifera genus, has been widely used in popular medicine for the treatment of several diseases. The aim of this study was to investigate the antifungal activity of the copaiba oil and its isolated compounds caryophyllene oxide, copalic acid and acetoxycopalic acid against Trichophyton rubrum, Trichophyton mentagrophytes and Microsporum gypseum strains, using microdilution method and microscopy techniques. It was found that the copaiba oil and the copalic acid were active against dermatophytes by minimal inhibitory concentration (MIC) and minimal fungicidal concentration (MFC) tests. The MIC and MFC of copaiba oil against T. rubrum, T. mentagrophytes and M. gypseum were $125 \mu \mathrm{g} \mathrm{mL}^{-1}$ (250 $\left.\mu \mathrm{g} \mathrm{mL}^{-1}\right), 500 \mu \mathrm{g} \mathrm{mL}^{-1}\left(500 \mu \mathrm{g} \mathrm{mL}^{-1}\right)$ and $250 \mu \mathrm{g} \mathrm{mL}^{-1}\left(250 \mu \mathrm{g} \mathrm{mL}^{-1}\right)$, respectively. For copalic acid, the MIC and MFC were $50 \mu \mathrm{g} \mathrm{mL}^{-1}\left(100 \mu \mathrm{g} \mathrm{mL}^{-1}\right), 100 \mu \mathrm{g} \mathrm{mL}^{-1}\left(100 \mu \mathrm{g} \mathrm{mL}^{-1}\right)$ and $50 \mu \mathrm{g} \mathrm{mL}^{-1}$ $\left(100 \mu \mathrm{g} \mathrm{mL}^{-1}\right)$, respectively. Fluorescence microscopy and scanning electronic microscopy were used to investigate inhibition on hyphal growth by compounds, copaiba oil and copalic acid, showing a strong inhibition and an irregular growth pattern. Cell wall, cytoplasmic membrane and intracellular contents were also damaged. In conclusion, copaiba oil and copalic acid showed great activity against dermatophytes, being potential compounds for the development of antifungal drugs.
\end{abstract}

Keywords: Copaifera L., copaiba oil, dermatophytes, antifungal activity, copalic acid

\section{Introduction}

Copaiba oil is an oleoresin extracted from the trunk of several Copaifera L. species with trees native in tropical regions in Latin America and Western Africa. This oleoresin has been widely used in popular medicine due to its pharmacological properties, and studies have been performed to demonstrate its activity as anti-inflammatory, wound healing, antibiotic and fungicidal. ${ }^{1-11}$ Known as a transparent liquid with variable color and viscosity, copaiba oil consists in a mixture of sesquiterpenes and diterpenes that, isolated, also present several pharmacological activities. Studies of isolation, purification and characterization of these compounds have shown $\beta$-caryophyllene and its oxide as a chemical marker

*e-mail: npelopes@fcfrp.usp.br of sesquiterpenes fraction found in the copaiba oil. Among the diterpenes, copalic acid was considered a biomarker for the Copaifera genus. ${ }^{12}$

Dermatophytes are pathogenic fungi that utilize keratinous substrates as carbon, nitrogen and sulfur sources. They belong to three genera Trichophyton, Microsporum and Epidermophyton, which have the peculiar ability to digest and grow on keratinized host structures such as skin, hair and nails, causing superficial lesions. However, these fungi usually do not invade living tissues. Dermatophyte infections constitute one of the most important group of fungal infections in the world. Although they do not cause outbreaks or pandemics, incidence of severe systemic fungal infections has increased, mainly due to patients with compromised immune system. ${ }^{13,14}$

Clinically important antifungals have drawbacks in terms of toxicity, efficacy and cost. These factors and the 
emergency of resistant strains have led to the search for novel antifungals selectively acting on new targets with fewer side effects. Also, dermatophytosis treatments are, in general, expensive and must be applied over long periods. Thus, developing new drugs with improved efficacy and safety is needed. Plants, either as pure compounds or standardized extracts, are potential sources for new pharmaceuticals. $^{15}$

In a recent work, Zimmermam-Franco et al. ${ }^{16}$ have shown that the oleoresin from $C$. langsdorffii presents great activity against dermatophytes. Thus, the study of the major compounds from copaiba oil and its activity against dermatophytes seems interesting.

\section{Experimental}

\section{Plant material}

Commercial copaiba oil was obtained from a cooperative centre (Rio Branco-AC, Brazil) collected in 1999 at Tarauaca region and commercialized in 2000.

Isolation of copalic acid, acetoxycopalic acid and caryophyllene oxide

Commercial copaiba oil was solubilized in hexane in order to obtain the organic fraction of the oil and then the hexane was evaporated and the fraction was concentrated under pressure at $70{ }^{\circ} \mathrm{C}$. Next, $5.686 \mathrm{~g}$ of the concentrated copaiba oil was fractionated by liquid chromatography in silica gel 60, 70-230 mesh. Elution was conducted by gradient mobile phase starting with hexane and finishing with ethyl acetate. 169 fractions, with $300 \mathrm{~mL}$ each, were obtained. These fractions were concentrated in a rotatory evaporator and analyzed by thin layer chromatography (TLC). Caryophyllene oxide was obtained in fractions 28-37 eluted with mobile phase 99\% hexane and $1 \%$ ethyl acetate, while copalic acid and acetoxycopalic acid were obtained in fractions 57-64 and 135-150, respectively. Copalic acid was eluted with mobile phase $98 \%$ hexane and $2 \%$ ethyl acetate, and acetoxycopalic acid was eluted with mobile phase $90 \%$ hexane and $10 \%$ ethyl acetate. The structures of the isolated compounds were elucidated by ${ }^{1} \mathrm{H}$ nuclear magnetic resonance (NMR) (400 MHz, $\left.\mathrm{CDCl}_{3}\right)$ and ${ }^{13} \mathrm{C}$ NMR $\left(100 \mathrm{MHz}, \mathrm{CDCl}_{3}\right)$. The purity of the fraction was evaluated by liquid chromatography with diode array detector mass spectrometry (LC-DAD-MS) or gas chromatography-MS (GC-MS). ${ }^{1} \mathrm{H},{ }^{13} \mathrm{C}$, and $2 \mathrm{D}$ NMR spectra were acquired on a Bruker DRX 400 spectrometer with the deuterated solvents $\mathrm{CD}_{3} \mathrm{OD}(\delta 3.31)$, used as internal standards. LC-DAD-MS were conducted on a Shimadzu LC-20A apparatus equipped with a diode array detector (SPD-M20AV, Shimadzu) and coupled to an UltrOTOFq (Bruker Daltonics) ESI-qTOF mass spectrometer. The work was under $\mathrm{CNPq}$ licence for research (010808/2014-0).

\section{Strains and growth conditions}

The dermatophyte strains Trichophyton rubrum ATCC 28189, Trichophyton mentagrophytes ATCC 11480 and Microsporum gypseum ATCC 14683 were used in this study. They were cultured at $28^{\circ} \mathrm{C}$ on Sabouraud dextrose agar tubes during about 20 days before experiments. Spores were collected in sterile saline and suspensions were adjusted to $1.0 \times 10^{5}$ spores $\mathrm{mL}^{-1}$.

\section{Microdilution MIC determination}

The minimal inhibitory concentrations (MIC) of the oil and isolated copalic acid, acetoxycopalic acid and caryophyllene oxide, for fungal strains were determined according to the M38-A2 broth microdilution reference procedure of the $\mathrm{CLSI}^{17}$ at a inoculum of $0.4 \times 10^{4}$ to $5 \times 10^{4} \mathrm{CFU} \mathrm{mL}^{-1}$, using RPMI 1640 medium (Roswell Park Memorial Institute Medium) with L-glutamine without bicarbonate buffered with 0.165 M MOPS (morpholino propanesulfonic acid). Serial two-fold dilutions of the copaiba oil and isolated copalic acid, acetoxycopalic acid and caryophyllene oxide were done in a microdilution plate (96 wells) containing $100 \mu \mathrm{L}$ of sterile RPMI. Next, the inoculum was added to each well. Microplates were incubated at $28{ }^{\circ} \mathrm{C}$ for $72 \mathrm{~h}$. The MIC was defined as the lowest concentration which resulted in the inhibition of visual growth. Minimal fungicidal concentrations (MFC) were determined by subculturing $10 \mu \mathrm{L}$ of the culture from each negative well and from the positive control in Sabouraud dextrose agar.

\section{Checkerboard}

Checkerboard tests by broth microdilution method were performed to determine in vitro interactions between drugs against dermatophyte species. Copalic acid was tested in association with antifungal agents fluconazole or amphotericin B. Copalic acid was also tested with acetoxycopalic acid and with caryophyllene oxide.

\section{Fluorescence microscopy - hyphal growth inhibition}

Sub-inhibitory concentration of copaiba oil and copalic acid in $500 \mu \mathrm{L}$ of RPMI medium were prepared in 24-well 
plates containing cover slips. Wells were inoculated with $100 \mu \mathrm{L}$ of spore suspension containing 2000-3000 spores and the plate was incubated at $37{ }^{\circ} \mathrm{C}$ during $48 \mathrm{~h}$. Cover slips with adhered cells were carefully removed and washed in PBS (phosphate buffered saline) pH 7.2, with manual shaking, and fixed in absolute methanol and air dried. Cells were stained with Calcofluor White M2R (Sigma, St. Louis, MO, USA) and mounted on a slide. Slides were observed in an Olympus fluorescent microscope.

\section{Scanning electronic microscopy (SEM)}

For scanning electron microscopy (SEM), dilutions of the copaiba oil and copalic acid were done in a microdilution plate (96 wells) containing $100 \mu \mathrm{L}$ of sterile RPMI 1640. The inoculum was added to each well. Next, sterile nail fragments were added to each well. The microplates were incubated at $28^{\circ} \mathrm{C}$ for $72 \mathrm{~h}$. After fungal growth, nail fragments were processed for microscopy, they were dehydrated in graded ethanol, critical-point dried in $\mathrm{CO}_{2}$, coated with gold, and examined in a Shimadzu SS-550 scanning electron microscope.

\section{Transmission electronic microscopy (TEM)}

Dermatophytes treated with the oil and copalic acid during $72 \mathrm{~h}$ and control cells without treatment were fixed with $2.5 \%$ glutaraldehyde in $0.1 \mathrm{M}$ cacodylate buffer, $\mathrm{pH}$ 7.2. Post fixation was carried out in $2 \% \mathrm{OsO}_{4}$ in $0.2 \mathrm{M}$ cacodylate buffer ( $\mathrm{pH}$ 7.2) containing $1.6 \%$ potassium ferrocyanide and $10 \mathrm{mM} \mathrm{CaCl}_{2}$ for $120 \mathrm{~min}$ at room temperature. Thereafter, the cells were dehydrated in acetone and embedded in SPURR. Ultrathin sections were stained with uranyl acetate and lead citrate, and observed in a JEOL JEM 1400 transmission electron microscope.

\section{Results and Discussion}

The fractions obtained from copaiba oil were analyzed by TLC and separated according to their chromatographic profiles. Caryophyllene oxide (1) was eluted in the first fractions due to its nonpolar characteristics, while copalic acid (2) and acetoxycopalic acid (3) could be eluted only with a more polar mobile phase (Figure 1). Only fractions with high purity, with a single spot in the TLC analysis, were analyzed by ${ }^{1} \mathrm{H}$ and ${ }^{13} \mathrm{C}$ NMR, and their profiles were compared with the literature, enabling the elucidation of their structures (Figures S1-S6, Supplementary Information).

It has been reported commercial copaiba oils obtained from different species of Copaifera genus
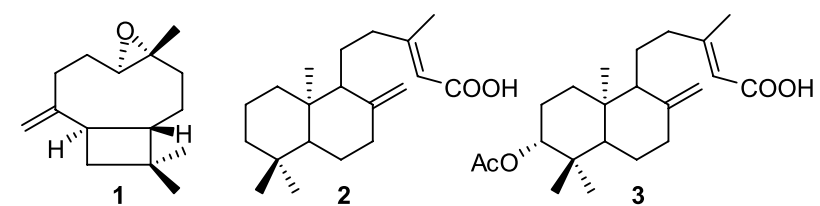

Figure 1. Molecular structure of the compounds isolated from copaiba oil. (1) Caryophyllene oxide (MW: $220.356 \mathrm{~g} \mathrm{~mol}^{-1}$ ); (2) copalic acid (MW: $304.474 \mathrm{~g} \mathrm{~mol}^{-1}$ ) and (3) acetoxycopalic acid (MW: $362.51 \mathrm{~g} \mathrm{~mol}^{-1}$ ).

have presented activity against Gram-positive bacteria Staphylococcus aureus, methicillin-resistant S. aureus, Staphylococcus epidermidis, Bacillus subtilis, and Enterococcus faecalis. Moderate effect has been observed against T. rubrum and M. canis. ${ }^{11}$ Deus et al. ${ }^{10}$ have reported oleoresin from $C$. multijuga Hayne inhibited growth of Aspergillus flavus and Candida parapsilosis. Terpenes from Copaifera oleoresins have also been effective against protozoa parasites Trypanosoma cruzi and Leishmania amazonensis. ${ }^{18,19}$ Other terpenes, as sesquiterpene lactones, have inhibited fungal growth of C. albicans and Cryptococcus neoformans. ${ }^{20}$ Copalic acid has demonstrated effectivity against cariogenic bacteria Streptococcus salivarius, S. sobrinus, S. mutans, S. mitis, S. sanguinis and Lactobacillus casei, as well as, against bovine mastitis bacteria $S$. aureus, S. epidermidis, Streptococcus agalactie and S. dysagalactie. ${ }^{21,22}$ In this report, we investigated the activity of copaiba oil, isolated copalic acid, acetoxycopalic acid and a fraction rich in caryophyllene oxide against dermatophyte species. MIC and MFC were determined and both copaiba oil and copalic acid were active against dermatophytes (Table 1). Tests were performed in triplicate and results were reproducible. Fungicidal concentrations (values between brackets) were the same or just one- or two-fold dilution above the inhibitory concentration. Acetoxycopalic acid was not active against the tested strains and the fraction rich in caryophyllene oxide showed only a weak inhibition of fungal growth at $1000 \mu \mathrm{g} \mathrm{mL}^{-1}$. By checkerboard, no interaction between copalic acid and antifungal agents was observed. Neither copalic acid and acetoxycopalic acid nor copalic acid and the fraction rich in caryophyllene oxide demonstrated synergistic activity against dermatophytes. However, interesting synergistic interactions between copalic acid and $\beta$-caryophyllene have been observed against $T$. cruzi. ${ }^{18}$

Table 1. Minimal inhibitory and minimal fungicidal concentrations (MIC and MFC) in $\mu \mathrm{g} \mathrm{mL} \mathrm{L}^{-1}$ of oil and copalic acid against dermatophytes species

\begin{tabular}{lccc}
\hline & \multicolumn{3}{c}{ MIC (MFC) / $\left(\mu \mathrm{g} \mathrm{mL}^{-1}\right)$} \\
\cline { 2 - 4 } & T. rubrum & T. mentagrophytes & M. gypseum \\
\hline Copaiba oil & $125(250)$ & $500(500)$ & $250(250)$ \\
Copalic acid & $50(100)$ & $100(100)$ & $50(100)$ \\
\hline
\end{tabular}


Toxic effects of oil-resin and copalic acid were evaluated against the tested fungi under fluorescence microscopy. In Figure 2, microscopy images show intense fluorescence on hyphal growth with continuous and healthy hyphae in control cells (Figures 2A, 2D and 2G of T. rubrum, T. mentagrophytes and M. gypseum). Strong reduction in hyphal growth occurred in fungi treated with copaiba oil (Figures 2B, 2E and $2 \mathrm{H}$ ) at sub-inhibitory concentrations of $31.2,125$ and $62.5 \mu \mathrm{g} \mathrm{mL} \mathrm{m}^{-1}$, respectively, and copalic acid (Figures 2C, 2F and 2I) at concentrations of $15.6,62.5$ and $31.2 \mu \mathrm{g} \mathrm{mL}{ }^{-1}$, respectively, when compared with control cells. Irregular growth, short hyphae and some non-germinated conidia were observed. Some hyphae and non-germinated conidia are less fluorescent than control cells. Calcofluor white is a nonspecific fluorochrome that binds to chitin in cell walls. Chitin is synthesized by enzymes present in the plasma membrane, then, any alteration in plasma membrane will have effect on cell wall chitin structure. Consequently, the cell wall damage will be evident by generating lower intensities of fluorescence compared to normal undamaged cell wall. ${ }^{23}$ Koroishi et al. ${ }^{24}$ have shown the inhibition of conidial germination of T. rubrum caused by neolignans isolated from Piper regnellii. Thiosemicarbazide camphene derivative affects and damages cell wall structure of T. mentagrophytes, which could be observed by Calcofluor white staining. ${ }^{25}$

To explore possible interaction of copaiba oil with fungal cell wall and membrane, tested strains were subject to electron microscopy after treatment with subinhibitory concentrations of oil and copalic acid. Scanning electron microscopy shows intense hyphal growth for T. mentagrophytes, T. rubrum and M. gypseum control cells (Figures 3A, 3D and 3G, respectively). Untreated cells of three species exhibited healthy hyphal structures, filaments with uniform width, cylindrical morphology and smooth appearance. A strong inhibition of hyphal growth and irregular growth pattern are observed in fungi treated with oil (Figures 3B, 3E and 3H) and copalic acid (Figures 3C, 3F and 3I). T. mentagrophytes
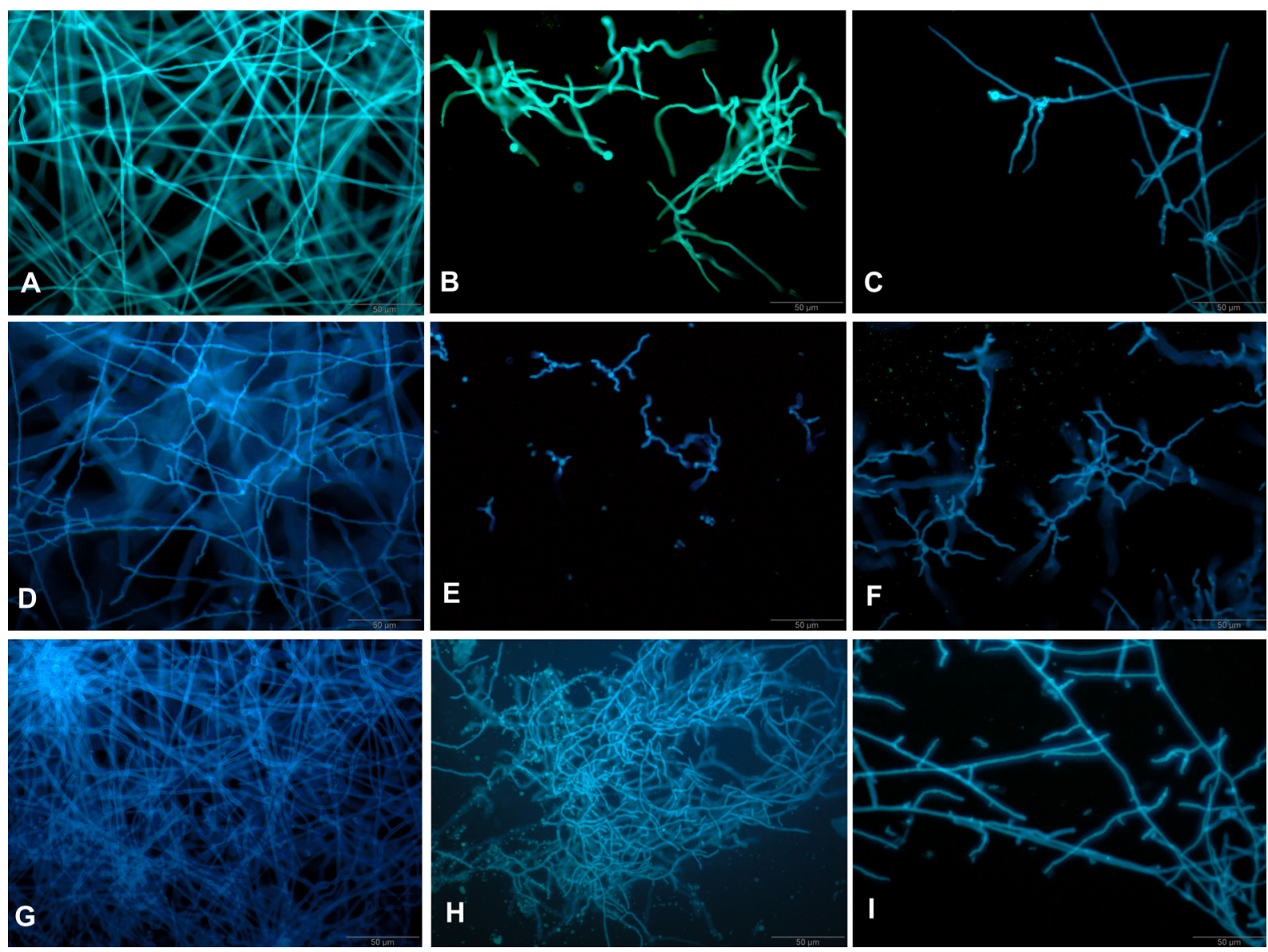

Figure 2. Calcofluor white fluorescence microscopy images after $48 \mathrm{~h}$ of treatment with sub-inhibitory concentrations of copaiba oil and copalic acid. (A) T. rubrum control without treatment; (B) T. rubrum treated with $31.6 \mu \mathrm{g} \mathrm{mL}-1$ of copaiba oil; (C) T. rubrum treated with $15.6 \mu \mathrm{g} \mathrm{mL} \mathrm{m}^{-1}$ of copalic acid; (D) T. mentagrophytes control without treatment; (E) T. mentagrophytes treated with $125 \mu \mathrm{g} \mathrm{mL}^{-1}$ of copaiba oil; (F) T. mentagrophytes treated with $62.5 \mu \mathrm{g} \mathrm{mL}{ }^{-1}$ of copalic acid; (G) M. gypseum control without treatment; (H) M. gypseum treated with $62.5 \mu \mathrm{g} \mathrm{mL} \mathrm{H}^{-1}$ of copaiba oil; (I) M. gypseum treated with $31.2 \mu \mathrm{gL}^{-1}$ of copalic acid. 
treated with $250 \mu \mathrm{g} \mathrm{mL}^{-1}$ of copaiba oil and $25 \mu \mathrm{g} \mathrm{mL} \mathrm{m}^{-1}$ of copalic acid (Figures 3B and 3C) showed short and stubby hyphae. T. rubrum treated with $31.2 \mu \mathrm{g} \mathrm{mL} \mathrm{m}^{-1}$ of copaiba oil and $12.5 \mu \mathrm{g} \mathrm{mL}-1$ of copalic acid (Figures $3 \mathrm{E}$ and $3 \mathrm{~F}$ ) were strongly inhibited and short hyphae are present. M. gypseum treated with $62.5 \mu \mathrm{g} \mathrm{mL}^{-1}$ of copaiba oil and $25 \mu \mathrm{g} \mathrm{mL} \mathrm{m}^{-1}$ of copalic acid (Figures $3 \mathrm{H}$ and 3I) was the most inhibited strain, only a few hyphae are seen when compared to control cells. Short hyphae have been observed not only by fluorescence microscopy in Aspergillus fumigatus treated with micafungin, but also by optical microscopy in cells treated with caspofungin, a $\beta$-glucan synthesis inhibitor. ${ }^{26,27}$ Thus, this study raises the possibility that both the oil and copalic acid are directly or indirectly interfering with fungal cell wall.

Transmission electron microscopy shows normal cells with intact membrane and cell wall and dense cytoplasm for T. mentagrophytes and M. gypseum (Figures $4 \mathrm{~A}$ and $4 \mathrm{C}$, respectively). After treatment with 250 and $62.5 \mu \mathrm{g} \mathrm{mL}^{-1}$ of copaiba oil, T. mentagrophytes and $M$. gypseum presented serious damages on cell wall and cytoplasmic membrane (Figures 4B and 4D, respectively), which corroborates with alterations observed by fluorescence microscopy. Furthermore, cytoplasm and its components are seriously damaged. In treated M. gypseum, the alteration of space between cell wall and cytoplasmic membrane led to deformed cells. Hydrophobic components from oil may pass through cellular membrane and change its permeability, which, in turn, lead to organelles disintegration or collapse, decrease of electron density, formation of cystic space, restrain on the mycelia growth, formation and germination of spores, and consequently, to the decay and death of the fungi. ${ }^{28}$ This could explain alterations observed by microscopic techniques on dermatophytes treated with copaiba oil and/or copalic acid. It is speculated that copaiba oil-resin could change permeability of fungal cells, leading to cell death. ${ }^{16}$ Lipophilic properties of oils facilitate the penetration on cell membrane and decrease conidial and mycelial growth, biomass production and morphogenesis. ${ }^{29}$ Some common alterations in dermatophytes observed by electron microscopy included lysis of cells, endoplasmic reticulum expansion near cell membrane, excessive vacuolization, disintegration of mitochondria, plasma membrane, cell wall, and nuclear contents, abnormal distribution of polysaccharides and leakage of cytoplasmic contents. ${ }^{30}$ Terpenes, in general, cause disruption of cell membrane and some of them act on fungal mitochondria. ${ }^{31}$
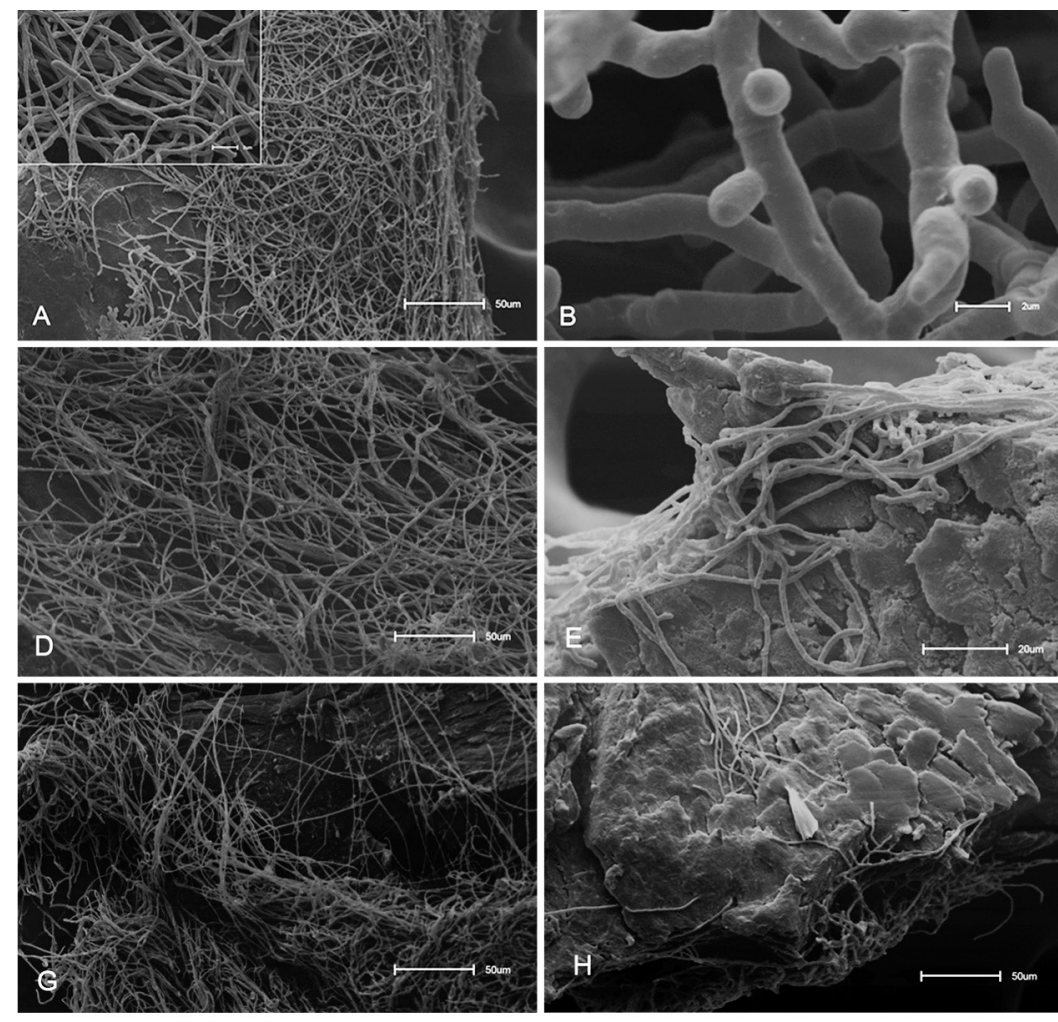
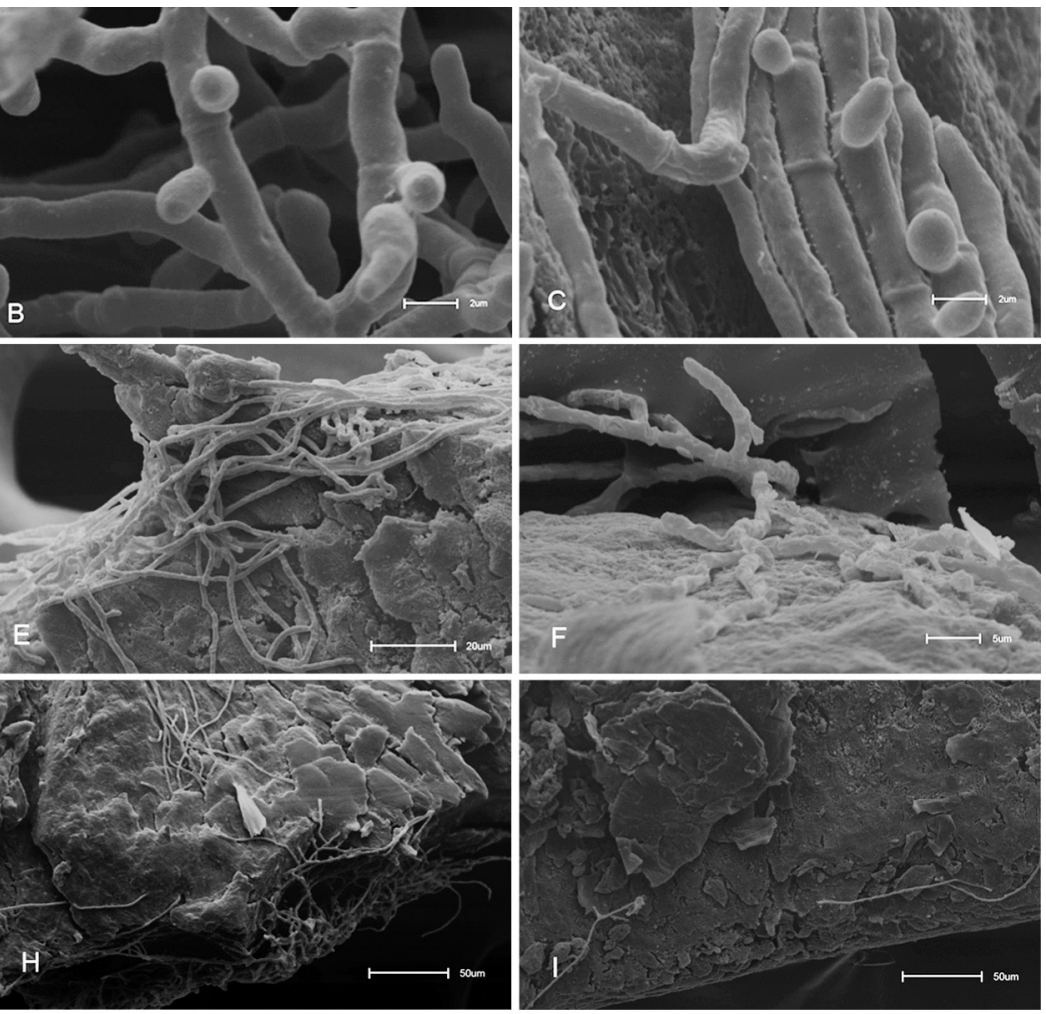

Figure 3. SEM images after treatment with sub-inhibitory concentrations of oil and copalic acid. (A) T. mentagrophytes control without treatment; (B) and (C) T. mentagrophytes treated with $250 \mu \mathrm{g} \mathrm{mL}-1$ of copaiba oil and $25 \mu \mathrm{g} \mathrm{mL} \mathrm{m}^{-1}$ of copalic acid; (D) T. rubrum control without treatment; (E) and (F) T. rubrum treated with $31.2 \mu \mathrm{g} \mathrm{mL}-1$ of copaiba oil and $12.5 \mu \mathrm{g} \mathrm{mL}^{-1}$ of copalic acid; (G) M. gypseum control without treatment; (H) and (I) M. gypseum treated with $62.5 \mu \mathrm{g} \mathrm{mL}-1$ of copaiba oil and $25 \mu \mathrm{g} \mathrm{mL} \mathrm{mL}^{-1}$ of copalic acid. 

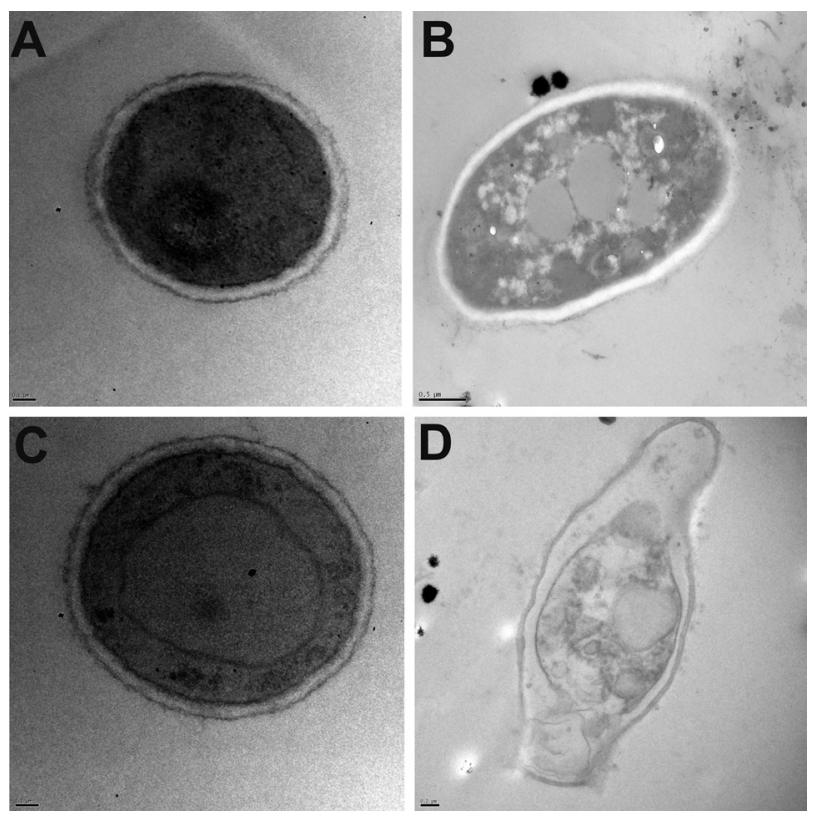

Figure 4. TEM images after treatment with sub-inhibitory concentrations of oil. (A) T. mentagrophytes control without treatment; (B) T. mentagrophytes treated with $250 \mu \mathrm{g} \mathrm{mL}^{-1}$ of oil; (C) M. gypseum control without treatment; (D) M. gypseum treated with $62.5 \mu \mathrm{g} \mathrm{mL} \mathrm{mL}^{-1}$ of oil.

Although many studies focus on biological properties of copaiba oil and its isolated compounds, there is little information about its antifungal effects. In this study, a fraction rich in caryophyllene oxide, acetoxi-copalic acid and copalic acid were obtained from copaiba oil, however only copaiba oil and copalic acid showed strong hyphal inhibition and changes in the growth pattern. Thus, suggesting they could be helpful in the development of antifungal strategies.

\section{Conclusion}

The present study reports the antifungal effect of copaiba oil and its isolated copalic acid against dermatophytes, with strong fungal inhibition and causing morphological alterations in their hyphae. Besides, copalic acid showed greater antifungal property than copaiba oil and no synergistic actions were observed with the fraction rich in caryophyllene oxide and acetoxy-copalic acid demonstrating that copalic acid is the most active compound in copaiba oil. Considering that copaiba oil has anti-inflammatory and wound healing properties, our results make it an interesting product to the development of new drugs for treatment of dermatophytosis.

\section{Supplementary Information}

Supplementary information is available free of charge at http://jbcs.sbq.org.br as a PDF file.

\section{Acknowledgments}

We are thankful to FAPESP (2014/50265-3), CAPES and $\mathrm{CNPq}$ for the financial support. This article is dedicated to Professor Angelo da Cunha Pinto.

\section{References}

1. Basile, A. C.; Sertié, J. A. A.; Freitas, P. C. D.; Zanini, A. C.; J. Ethnopharmacol. 1988, 22, 101.

2. Carvalho, J. C. T.; Cascon, V.; Possebon, L. S.; Morimoto, M. S. S.; Cardoso, L. G. V.; Kaplan, M. A. C.; Gilbert, B.; Phytother. Res. 2005, 19, 946.

3. Gomes, N. M.; Rezende, C. M.; Fontes, S. P.; Matheus, M. E.; Pinto, A. C.; Fernandes, P. D.; J. Ethnopharmacol. 2010, 128, 177.

4. Veiga Jr., V. F.; Zunino, L.; Calixto, J. B.; Patitucci, M. L.; Pinto, A. C.; Phytother. Res. 2001, 15, 476.

5. Veiga Jr., V. F.; Rosas, E. C.; Carvalho, M. V.; Henriques, M. G. M. O.; Pinto, A. C.; J. Ethnopharmacol. 2007, 112, 248.

6. Paiva, L. A. F.; Cunha, K. M. A.; Santos, F. A.; Gramosa, N. V.; Silveira, E. R.; Rao, V. S. N.; Phytother. Res. 2002, 16, 737.

7. Correia, A. F.; Segovia, J. F. O.; Gonçalves, M. C. A.; Oliveira, V. L.; Silveira, D.; Carvalho, J. C. T.; Kanzaki, L. I. B.; Eur. Rev. Med. Pharmacol. Sci. 2008, 12, 369.

8. Mendonça, D. E.; Onofre, S. B.; Rev. Bras. Farmacogn. 2009, 19, 577.

9. Santos, R. C. V.; Alves, C. F. S.; Schneider, T.; Lopes, L. Q. S.; Aurich, C.; Giongo, J. L.; Brandelli, A.; Vaucher, R. A.; J. Invertebr. Pathol. 2012, 109, 265.

10. Deus, R. J. A.; Alves, C. N.; Arruda, M. S. P.; Rev. Bras. Pl. Med. 2011, 13, 1.

11. Santos, A. O.; Ueda-Nakamura, T.; Dias Filho, B. P.; VeigaJunior, V. F.; Pinto, A. C.; Nakamura, C. V.; Mem. Inst. Osvaldo Cruz, 2008, 103, 277.

12. Leandro, L. M.; Vargas, F. S.; Barbosa, P. C. S.; Neves, J. K. O.; Silva, J. A.; Veiga-Junior, V. F.; Molecules 2012, 17, 3866.

13. Martinez-Rossi, N. M.; Peres, N. T. A.; Rossi, A.; Mycopathologia 2008, 166, 369.

14. Weitzman, I.; Summerbell, R. C.; Clin. Microbiol. Rev. 1995 , $8,240$.

15. Abad, M. J.; Ansuategui, M.; Bermejo, P.; Arkivoc 2007, 7, 116.

16. Zimmermam-Franco, D. C.; Bolutari, E. B.; Polonini, H. C.; Carmo, A. M. R.; Chaves, M. G. A. M.; Raposo, N. R. B.; Molecules 2013, 18, 12561.

17. Clinical and Laboratory Standards Institute; Reference Method for Broth Dilution Antifungals Susceptibility Testing of Conidium-Forming Filamentous Fungi: Approved Standard, $2^{\text {nd }}$ ed.; M38-A2; CLSI, Wayne, PA, USA, 2008.

18. Izumi, E.; Ueda-Nakamura, T.; Veiga-Junior, V. F.; Pinto, A. C.; Nakamura, C. V.; J. Med. Chem. 2012, 55, 2994. 
19. Santos, A. O.; Izumi, E.; Ueda-Nakamura, T.; Dias Filho, B. P.; Veiga-Junior, V. F.; Nakamura, C. V.; Mem. Inst. Osvaldo Cruz 2013, 108, 59.

20. Férnandez, L. R.; Butassi, E.; Svetaz, L.; Zacchino, S. A.; Palermo, J. A.; Sánchez, M.; J. Nat. Prod. 2014, 77, 1579.

21. Fonseca, A. P.; Estrela, F. T.; Moraes, T. S.; Carneiro, L. J.; Bastos, J. K.; dos Santos, R. A.; Ambrósio, S. K.; Martins, C. H. G.; Veneziani, R. C.; Molecules 2013, 18, 7865.

22. Souza, A. B.; Martins, C. H. G.; Souza, M. G. M.; Furtado, N. A. J. C.; Heleno, V. C. G.; Sousa, J. P. B.; Rocha, E. M. P.; Bastos, J. K.; Cunha, W. R.; Veneziani, R. C. S.; Ambrósio, S. R.; Phytother. Res. 2011, 25, 215.

23. Chaffin, W.; López-Ribot, J. L.; Casanova, M.; Gozalbo, D.; Martínez, J. P.; Microbiol. Mol. Biol. Rev. 1998, 62, 130.

24. Koroishi, A. M.; Foss, S. R.; Cortez, D. A. G.; Ueda-Nakamura, T.; Nakamura, C. V.; Dias Filho, B. P.; J. Ethnopharmacol. 2008, $117,270$.

25. Yamaguchi, M. U.; Silva, A. P. B.; Ueda-Nakamura, T.; Dias Filho, B. P.; Silva, C. C.; Nakamura, C. V.; Molecules 2009, 14, 1796.
26. Verwer, P. E. B.; van Duijin, M. L.; Tavakol, M.; BakkerWoudenberg, I. A. J. M.; van de Sande, W. W. J.; Antimicrob. Agents Chem. 2012, 56, 1595.

27. Watabe, E.; Nakai, T.; Matsumoto, S.; Ikeda, F.; Hatano, K.; Antimicrob. Agents Chem. 2003, 47, 1995.

28. Tao, C.; Wei, Q.; Yin, Z. Q.; Zhou, L. J.; Jia, R. Y.; Xu, J.; Shi, D. X.; Zhou, Y.; Du, Y. H.; Deng, Y. X.; Afr. J. Pharm. Pharmacol. 2013, 7, 1148.

29. Khan, M. S. A.; Ahmad, I.; Phytomedicine 2011, 19, 48.

30. Zuzarte, M.; Gonçalves, M. J.; Canhoto, J.; Salgueiro, L. In Science Against Microbial Pathogens: Communicating Current Research and Technological Advances. Microbiology Book Series, vol. 3; Méndez-Vilas, A., ed.; Formatex Research Center: Badajoz, Spain, 2011, p. 1167.

31. Freiesleben, S. H.; Jäger, A. K.; Med. Aromat. Plants 2014, 3,1 .

Submitted: June 25, 2016

Published online: November 29, 2016 